\title{
Quantitative, Competitive PCR Assay for HIV-1 Using a Microplate-Based Detection System
}

BioTechniques 24:810-816 (May 1998)

\author{
Patricia C. Guenthner and \\ Clyde E. Hart \\ Centers for Disease Control \\ and Prevention, Atlanta, GA, \\ USA
}

\begin{abstract}
We have developed a quantitative competitive PCR (QC-PCR) assay in a microplate format for quantifying human immunodeficiency virus Type 1 (HIV-1) DNA or RNA in a broad range of source materials. Our QC-PCR assay is a modification of technique originally described by Piatak et al. (1993), which is based on the presence of a competitive internal standard containing an internal 80-bp deletion of HIV-1 gag target sequence. For improved detection and quantification of the wild-type and internal-standard PCR products in a microplate format, we introduced a non-HIV, 31-bp insert into the internal standard as a probe hybridization site that does not crosshybridize with wild-type HIV-1 products. By using a primer pair in which one primer is biotinylated, QC-PCRs can be bound to a streptavidin-coated microplate, denatured and probed with a digoxigenin (Dig)-labeled, wild-type or internal-standard probe. The hybridized Dig-labeled probes are detected with an anti-Dig antibody conjugated to detector molecules for luminometry (AIDS) $\quad(4,10,11,15,16)$. Accurate quantification of the viral load in peripheral blood has therefore been used extensively in the clinical management of HIV-1-infected persons and for the study of HIV-1-associated pathogenesis and transmission $(6,8)$. However, there is a growing interest in quantifying HIV-1 RNA and proviral DNA in tissues and body fluids other than peripheral blood $(1,13,20,21,30)$. Commercially available HIV-1 viral load assays that use signal amplification (29) or the polymerase chain reaction (PCR) (17, 18) were developed and are recommended for quantifying viral RNA exclusively from plasma. Here we report the development of a quantitative competitive (QC)-PCR (22-24) and a microplate detection system that uses digoxigenin (Dig)-labeled probes and an anti-Dig antibody conjugated to a bioluminescent protein (aequorin; References 5, 9 and 25-28) or peroxidase that is easy, relatively inexpensive and quantifiable to 100 copies of HIV-1 DNA or RNA per extracted sample.
\end{abstract} (aequorin) or optical densitometry (peroxidase), yielding results that are quantifiable over the range of 100-10000 copies of HIV gag. Tested source materials for HIV-1 DNA or RNA quantification include plasma, vaginal lavage and cultured cells. The application of the QC-PCR assay using the microplate format affords a convenient and cost-effective method for quantifying HIV-1 proviral and viral loads from a variety of body fluids, cells and tissues.

\section{INTRODUCTION}

The amount of virus in the peripheral blood of a human immunodeficiency virus Type 1 (HIV-1)-infected individual is a strong predictor of HIV-1-associated illness and progression to acquired immunodeficiency syndrome

\section{MATERIALS AND METHODS}

\section{HIV-1 Internal Standard Plasmid Construction and RNA Synthesis}

The plasmids pQP1-p (wild-type positive control) and pQP1 880 -p (original internal standard) Bluescript ${ }^{\circledR}$ KS plasmids (Stratagene, La Jolla, CA,
USA), from M. Piatak (Genelabs Technologies, Redwood City, CA, USA), contain a 1420-bp SacI/BglII fragment from the gag gene of HIV-I HXB2c. The pQP1880 contains an 80-bp deletion of the $\mathrm{SacI} / \mathrm{Bg} / \mathrm{II}$ fragment. We constructed a new internal standard from $\mathrm{pQP} 1 \delta 80$ by inserting a nonhomologous 31-bp fragment from pBR327 into the SphI site in gag. This new construct was designated $\mathrm{pQP} 1 \delta 50$ DNA ( $\delta 50 \mathrm{D}$; Figure 1A).

The internal standard $850 \mathrm{D}$ and the positive-control plasmid pQP1 were prepared by linearization of the plasmid with EcoRI, proteinase $\mathrm{K}$ digestion, phenol extraction and precipitation. On reconstitution in distilled $\mathrm{dH}_{2} \mathrm{O}, \delta 50 \mathrm{D}$ and $\mathrm{pQP} 1$ concentrations were determined by optical density (OD), the copy numbers were determined and single-use aliquots were stored at $-70^{\circ} \mathrm{C}$. HIV-1 RNA internal-standard ( $850 \mathrm{R}$; Figure 1A) and positive-control (QP1R) templates were transcribed in vitro from the T7 promoter of EcoRIlinearized plasmid DNA with an RNA Transcription Kit (Stratagene) using 1 $\mu \mathrm{g}$ of DNA template in a $50-\mu \mathrm{L}$ reaction mixture. After DNase (Boehringer Mannheim, Indianapolis, IN, USA) treatment at $37^{\circ} \mathrm{C}$ for $15 \mathrm{~min}$, RNA templates were purified by using RNAzol $^{\mathrm{TM}}$ B (Tel-Test, Friendswood, TX, USA) as per the manufacturer's protocol, and copy numbers were determined from optical density readings. Aliquots of the RNA templates were run on a formaldehyde gel to ensure the transcripts were of full length.

\section{Specimen DNA and RNA Isolation and PCR}

Cellular DNA was isolated by using a Total DNA Isolation Kit (Gentra 
Systems, Minneapolis, MN, USA) as per the manufacturer's protocol. To isolate genomic viral RNA, cell-free HIV1 was pelleted $(100000 \times g)$ for $1 \mathrm{~h}$ at $4^{\circ} \mathrm{C}$, from $1-\mathrm{mL}$ aliquots of human plasma and vaginal phosphate-buffered saline (PBS) lavage that had been cleared of cells by centrifugation at $400 \times g$ for $15 \mathrm{~min}$ at room temperature. RNA from the pelleted virus was isolated by using a fast guanidinium isothiocyanate procedure described by Mulder et al. (17).

Primers GAG04 (CATICTATTTGT-
TCITGAAGGGTACTAG-3') and GAG06 (GTACCCATAAITGAAGICCCGAITTICG-5') designed by Piatak et al. (22), incorporate inosines at those positions known for sequence divergence $(3,19)$. The antisense primer was biotinylated (GAG04-B). The GAG06/GAG04-B primer pair yields products of $260 \mathrm{bp}$ from QP1 or wild-type HIV-1 and yields $211 \mathrm{bp}$ from the internal standard $\delta 50$. Reverse transcription (RT)-PCR was carried out as previously described (22) with the following modifications. Four concentrations of

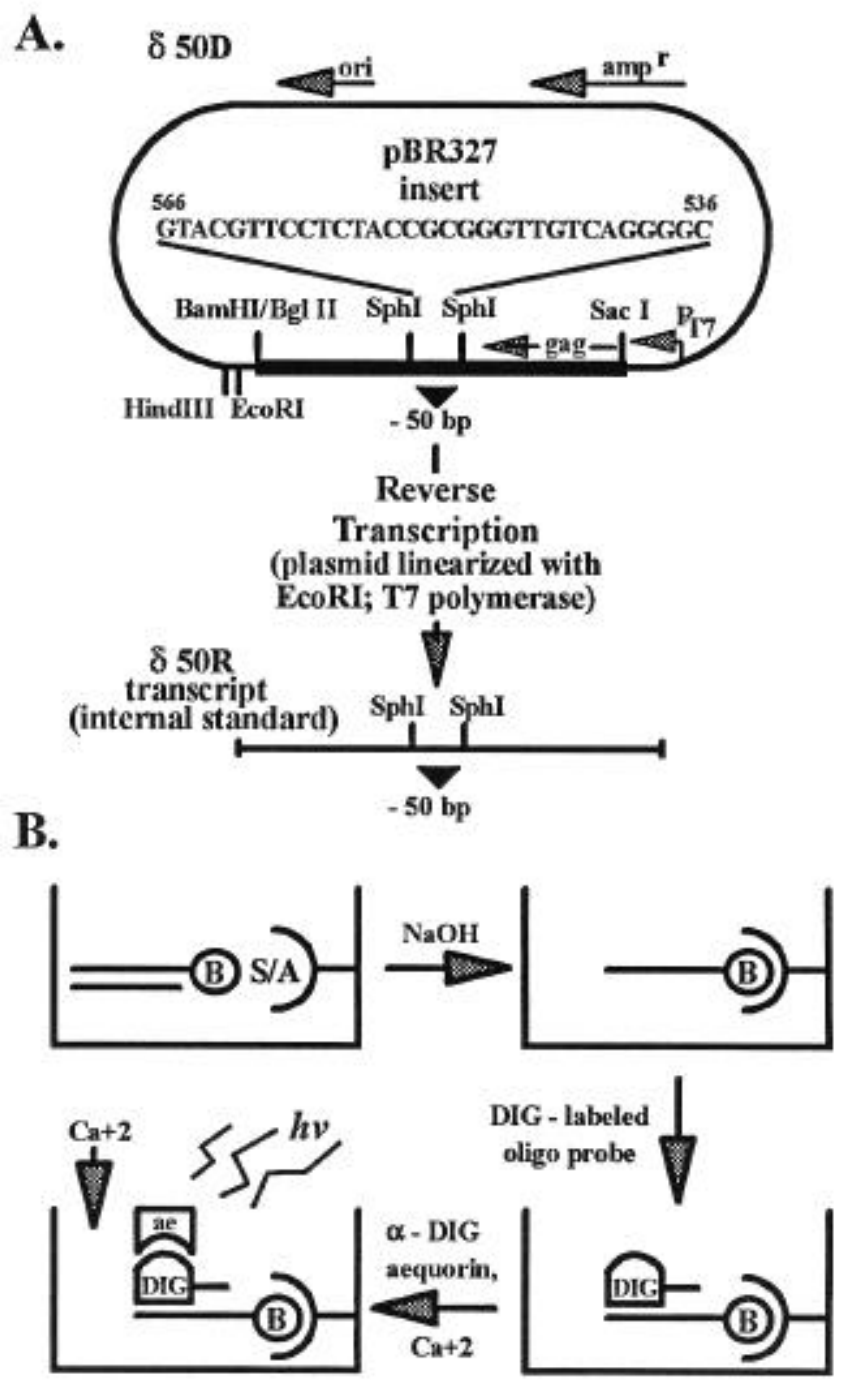

Figure 1. (A) $\delta 50$ plasmid DNA and RNA internal standards. The original pQP1 $\delta 80-p B l u e s c r i p t$ plasmid by Piatak et al. (22) was modified by inserting a 31-bp fragment from pBR327 into the $S p h$ I restriction site. A plasmid clone containing the 31-bp insert with the orientation shown here was used as the HIV-1 DNA internal standard ( $\delta 50 \mathrm{D})$ and for generation of the RNA internal standard ( $\delta 50 \mathrm{R})$. (B) Quantification of biotinylated QC-PCR products by luminometry in a streptavidin-coated microplate assay.

internal standard $\left(10^{1}, 10^{2}, 10^{3}\right.$ and $10^{4}$ copies) plus a constant amount of nucleic acid to be quantified were added to four individual PCRs or RT-PCRs. RT was done using random hexamers and the GeneAmp ${ }^{\circledR}$ RNA PCR Kit (Perkin-Elmer, Norwalk, CT, USA) in $30 \mu \mathrm{L}$ per the manufacturer's protocol: $42^{\circ} \mathrm{C}$ for $45 \mathrm{~min}, 99^{\circ} \mathrm{C}$ for $5 \mathrm{~min}$, and maintained at $4^{\circ} \mathrm{C}$. Following RT, 12.5 pmol of each primer (GAG04-B/ GAG06) and 0.5 U Taq DNA polymerase in $30 \mu \mathrm{L}$ were added in buffer conditions following the manufacturer's protocol (Perkin-Elmer). Cycling conditions were as previously reported (22), except that the annealing temperature was set at $55^{\circ} \mathrm{C}$. DNA QC-PCR was carried out in the same manner as the RNA QC-PCR minus the RT step, and each set of four PCRs contained the DNA internal standard 850D. Cycling conditions were as previously reported (22). PCR products were analyzed visually by electrophoresis on a $3 \%$ agarose gel and ethidium bromide staining, and by the microplate assay protocol described below.

\section{Quantification of QC-PCR Products in a Microplate Format}

For quantification in the microplate format, $5 \mu \mathrm{L}$ of the QC-PCRs were added to duplicate wells of a streptavidin-coated white microplate (Boehringer Mannheim) containing $195 \mu \mathrm{L}$ of hybridization buffer $(1 \times$ standard saline citrate [SSC], $20 \mathrm{mM}$ HEPES, $\mathrm{pH}$ 7.0, 2 mM EGTA, $0.1 \%$ Tween ${ }^{\circledR} 20$ ), and the plate was incubated for $30 \mathrm{~min}$ at $37^{\circ} \mathrm{C}$. The microplate wells were rinsed 6 times with $300 \mu \mathrm{L}$ of wash buffer (0.01M PBS, pH 7.2, $0.05 \%$ Tween 20, 2 mM EGTA) before the streptavidinbound, biotinylated PCR products were denatured $(250 \mu \mathrm{L} ; 0.4 N \mathrm{NaOH}, 0.6 \mathrm{M}$ $\mathrm{NaCl}$ ) for $15 \mathrm{~min}$ at room temperature and then rinsed as before. A Dig-labeled oligonucleotide probe (GGACATCAAGCAGCCATGCAAATGT;

$40 \mathrm{ng} /$ well) for detection of wild-type HIV-1 products was added to one set of wells in $200 \mu \mathrm{L}$ of hybridization buffer, and a $\delta 50$-specific Dig-oligonucleotide probe (TGTTGGGCGCCATCTCCTT$\mathrm{GC} ; 40 \mathrm{ng} /$ well) was added to the duplicate wells for $1 \mathrm{~h}$ at $37^{\circ} \mathrm{C}$ and rinsed as before (Figure 1B). 


\section{Diagnostic Techniques}

For quantitative luminometry, $5 \mathrm{ng}$ of an anti-Dig antibody conjugated to the bioluminescent aequorin protein (Sealite Sciences, Bogart, GA, USA) were added to each well in $200 \mu \mathrm{L}$ assay buffer (0.01 M PBS, pH 7.2, 0.5\% gelatin, $0.1 \%$ Tween 20, 2 mM EGTA), incubated at $37^{\circ} \mathrm{C}$ for $30 \mathrm{~min}$ and rinsed as before. The well-bound aequorin/Dig-antibody conjugate produced a transient light emission by the addition of a calcium/Tris trigger solution $\left(0.1 \mathrm{M} \mathrm{CaCl}_{2}, 0.05 \mathrm{M}\right.$ Tris- $\mathrm{HCl}$, $\mathrm{pH}$ 7.5), which was read in the integrate flash mode of a Model ML3000 Luminometer (Dynatech Laboratories, Chantilly, VA, USA) (Figure 1B).

By substituting an anti-Dig peroxidase-conjugated antibody for the antiDig aequorin conjugate, the microplate quantification reactions were performed with a colorimetric assay. The protocol for binding the biotinylated products to the streptavidin-coated wells, denaturation of the products and probe hybridization is identical to the luminometry protocol described above. After the probe hybridization wash, an anti-Dig peroxidase conjugate (DIG Detection ELISA (TMB) Kit; Boehringer Mannheim) is added at a 1:5000 dilution in $200 \mu \mathrm{L}$ per well of a blocking solution (PBS with $1 \%$ bovine serum albumin). The plate is incubated at $37^{\circ} \mathrm{C}$ for $1 \mathrm{~h}$, washed, and $200 \mu \mathrm{L}$ of the tetramethylbenzidine substrate, per the manufacturer's protocol, are added to each well. The microplate is incubated in the dark at room temperature for $10 \mathrm{~min}$, and the reaction is stopped by the addition of $100 \mu \mathrm{L}$ of $1 \mathrm{M}$ sulfuric acid per well. The OD of the wells are read in a standard microplate reader at $450 \mathrm{~nm}$ with a reference wavelength of $690 \mathrm{~nm}$.

The relative light units (RLU) or OD generated from wild-type and $850-$ probed samples were used to calculate HIV-1 copy number by using the known copy numbers of the $\delta 50$ internal standards. Calculation of input wild-type copies followed the method originally described by Piatak et al. (22). Briefly, the $\log _{10}$ of each of the four internal standard $\delta 50$ copy numbers $\left(10^{1}, 10^{2}, 10^{3}\right.$ and $\left.10^{4}\right)$ was plotted vs. the corresponding $\log _{10}(\delta 50 \mathrm{RLU}$ or OD/wild-type RLU or OD) for the four PCRs. Linear regression analysis of these four data points generated the
A.

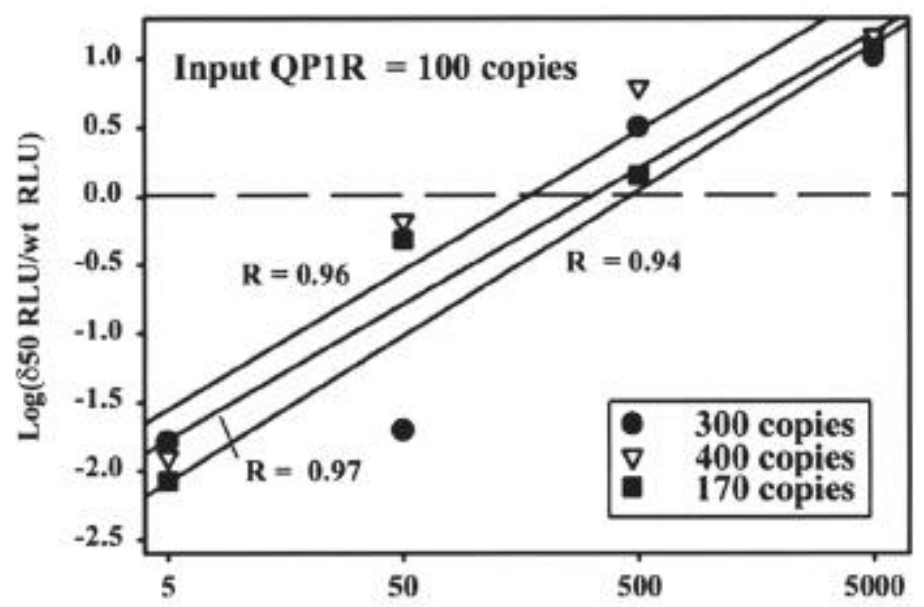

B.

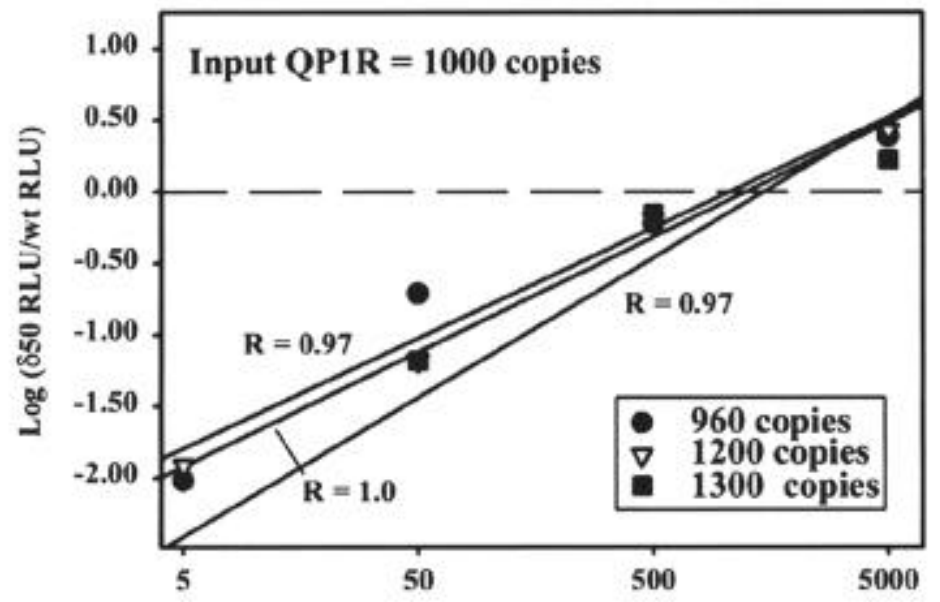

C.

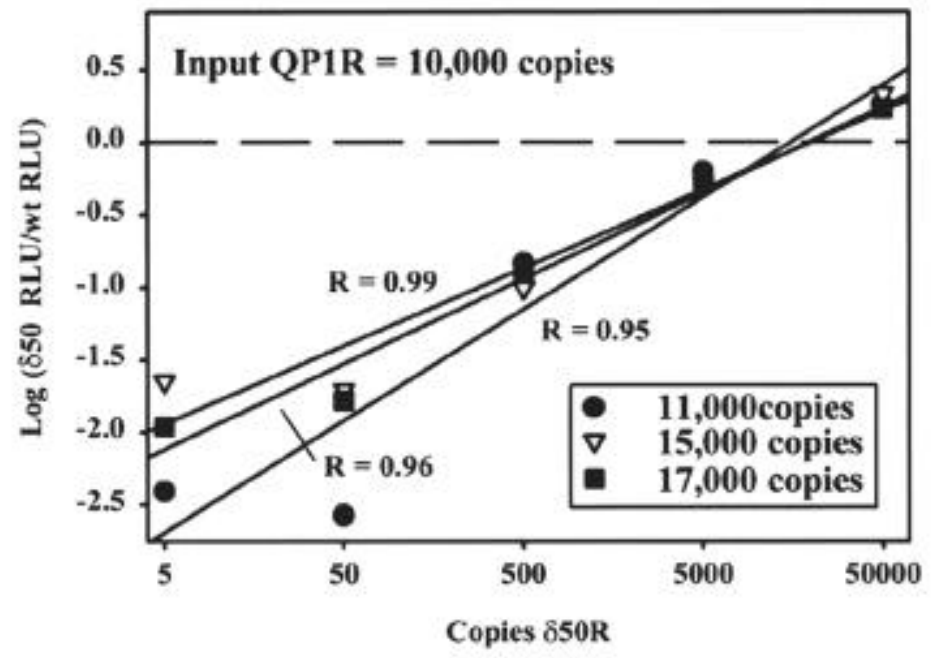

Figure 2. Quantification of HIV-1 RNA using the RT QC-PCR/microplate detection system. Input-QP1R at 100 copies (A), 1000 copies (B) and 10000 copies (C) was spiked into triplicate RT QCPCRs containing 5, 50, 500 and 5000 (and 50000 in Panel C) copies of $\delta 50 R$ internal standard. QP1 and $\delta 50$ products detected by the aequorin luminometry system were expressed as RLU. The three diagonal lines in each graph represent the linear regression curves used for the calculation of predicted copies of QP1R as described in Materials and Methods. Pearson's correlation coefficient (R) was determined for each set of data points. 
Table 1. Viral Load Quantification in Clinical Samples by the QC-PCR/Microplate Detection Assay

\begin{tabular}{|c|c|c|c|}
\hline \multirow[b]{2}{*}{ Sample } & \multicolumn{2}{|c|}{ Viral RNA (copies/mL) } & \multirow{2}{*}{$\begin{array}{c}\text { Fold } \\
\text { Difference } \\
\text { (QC-PCR/bDNA) }\end{array}$} \\
\hline & bDNAa & QC-PCR ${ }^{b}$ & \\
\hline Plasmac: 1 & 39000 & 24000 & 0.62 \\
\hline 2 & 500000 & 660000 & 1.32 \\
\hline 3 & 140000 & 110000 & 0.79 \\
\hline 4 & $<10000$ & 700 & $----d$ \\
\hline 5 & $<10000$ & 3100 & ---- \\
\hline Vaginal Lavagee & 100000 & 130000 & 1.30 \\
\hline \multicolumn{4}{|c|}{$\begin{array}{l}\text { abDNA is the Quantiplex HIV-RNA Branched DNA Detection System (Chiron, } \\
\text { Emeryville, CA, USA) used per the manufacturer's protocol for plasma HIV RNA } \\
\text { quantification. }\end{array}$} \\
\hline \multicolumn{4}{|c|}{ bQC-PCR was performed as described in Materials and Methods. } \\
\hline \multicolumn{4}{|c|}{$\begin{array}{l}\text { CPlasma samples from HIV-1-seropositive persons were drawn in acid citrate } \\
\text { dextrose CPT tubes (Becton Dickenson Labware, Bedford, MA, USA) and 1-mL } \\
\text { aliquots were stored at }-70^{\circ} \mathrm{C} \text { until use. }\end{array}$} \\
\hline \multicolumn{4}{|c|}{$\begin{array}{l}\text { dFold-difference calculation was not possible because of the out-of-range bDNA } \\
\text { signal. }\end{array}$} \\
\hline \multicolumn{4}{|c|}{$\begin{array}{l}\text { eVaginal lavages were collected as } 10 \mathrm{~mL} \text { PBS washes from HIV-1-seronegative } \\
\text { women, cleared of cells and stored at }-70^{\circ} \mathrm{C} \text { until use. Equal volumes of the } \\
\text { three lavages were mixed and spiked with HIV-1-positive plasma. }\end{array}$} \\
\hline
\end{tabular}

equation $(\mathrm{y}=\mathrm{mx}+\mathrm{b})$; calculating the $\mathrm{y}$ value at $0\left[\log _{10}(\delta 50 \mathrm{RLU}\right.$ or OD/wildtype RLU or OD) =0] yielded the equivalence point of the wild-type and $\delta 50$ products.

\section{RESULTS}

Preliminary experiments to develop a microplate-based detection assay, using the original internal standard (QP1 880$)$ were unsuccessful due to cross-reactivity between wild-type products and the $\delta 80$ probe. Creation of the new $\delta 50$ internal standard, which contains a probe hybridization site that is nonhomologous to HIV-1, and optimization of the probe hybridization conditions resulted in a more accurate QC-PCR/microplate detection system. Initial testing of samples in triplicate showed a greater difference between input copies and QC-PCR-predicted copies of HIV-1 RNA in the lower range of the assay. Intra-assay variation between QC-PCR-determined copy number and input HIV-1 RNA copy number was 1.7 -fold to 4.0 -fold at 100 input copies, 1.0-fold to 1.3 -fold at 1000 input copies and 1.1-fold to 1.7 fold at 10000 input copies (Figure 2).

Accurate quantification of QC-PCRs in the microplate format was also accomplished using a colorimetric, peroxidase-based detection method. An RT QC-PCR experiment was performed using 1500 input copies of QP1R. The PCR products were separated by gel electrophoresis on a $3 \%$ agarose gel, visualized by ethidium bromide staining (Figure 3A) and quantified by both the aequorin and peroxidase detection systems (Figure 3B). Visually, the ethidium bromide-stained gel indicates the equivalence point of the QP1R and $\delta 50 \mathrm{R}$ products to be between 1000 and 10000 input copies. Although the slopes of the lines generated by linear regression of the data points were noticeably different between the two detection methods, the copy number determined by the peroxidase-based assay and that which was determined by the 
aequorin-based assay (1600 copies) were both nearly equal to the predicted copy number of 1500 .

To evaluate the performance of the QC-PCR/microplate quantification procedure on clinical samples, HIV-1 RNA viral loads were determined for 1-mL plasma aliquots from five HIV-1 seropositive persons (Table 1). Viral load values on these plasma samples were also obtained by the branched DNA (bDNA) signal amplification technique (29) (Table 1). The viral load values obtained with the QC-PCR technique ranged from 660000 to 700 copies/mL of plasma; bDNA values on these same plasma samples ranged from 501890 to $<10000$ copies/mL. In three of the five plasma samples, the viral load values determined by QC-PCR were within twofold of the values obtained by bDNA. The remaining two plasma samples had viral loads that were below the limit of quantification by bDNA (<10000 copies/mL), which corresponded to the QC-PCR determination of 700 and 3000 copies $/ \mathrm{mL}$. These results indicate that this QCPCR technique is capable of quantifying HIV-1 virus from plasma at values comparable to those obtained from an HIV-1 viral load assay that has been shown to be reproducibly accurate (29) and that correlates well with the QCPCR assay (2).

This QC-PCR technique was also capable of quantifying proviral DNA and viral RNA in extravascular fluids. Aliquots $(200 \mu \mathrm{L})$ of HIV-1-containing plasma (Table 1, No. 2) were spiked into $800 \mu \mathrm{L}$ of a mixed PBS vaginal lavage, and virus was quantified using bDNA and QC-PCR methods for quantification of plasma virus. The predicted bDNA and QC-PCR values of 102000 and 130000 copies/1 mL of vaginal lavage, respectively, were accurately quantified from vaginal lavage (100000 and 130000 copies/mL, respectively). To test proviral DNA quantification from HIV-1-infected cells in vaginal lavage, $8 \mathrm{E} 5$ cells that contained one integrated copy of HIV-1 proviral DNA per cell (7) were spiked in an aliquot of mixed vaginal lavage $(1 \mathrm{~mL})$, and total DNA was isolated for the QC$\mathrm{PCR} /$ microplate detection assay. From the 20000 8E5 cell equivalents estimated to be in the PCRs, the DNA QC-PCR assay determined 20000 copies of proviral HIV-1 DNA (Figure 4). These data suggest that in normal vaginal lavage, there do not appear to be inhibitors of HIV-1 proviral or viral load quantification by our QC-PCR methods. However, a comparative study of viral load assays that use vaginal lavage from HIV-1-infected women is needed to examine the potential of this, or any other, viral load assay for accurately measuring HIV-1 in the female genital tract.

\section{DISCUSSION}

The QC-PCR/microplate detection assay described in this report was developed to be a viral quantification assay that could be adapted to accommodate both tissue and fluid specimens using instrumentation available in most laboratories capable of performing
PCR. Although HIV-1 QC-PCR methodology is not commercially available, it is highly adaptable. Depending on the nucleic acid extraction technique and whether the RT step is included, QCPCR can quantify proviral DNA, cellular RNA or viral RNA. For RNA extractions from cell-free virions, we have successfully used the procedure of Mulder et al. (17), without pelleting virus from plasma or spiked vaginal lavage, to accurately determine HIV-1 viral loads.

The use of either luminescent- or peroxidase-based quantification in the QC-PCR microplate format allows for differences in the availability of equipment in individual laboratories. Although HIV-1 quantification was very similar using the luminescent- and peroxidase-based assays in the tested range, further refinement of the peroxidase-based procedure would be neces-

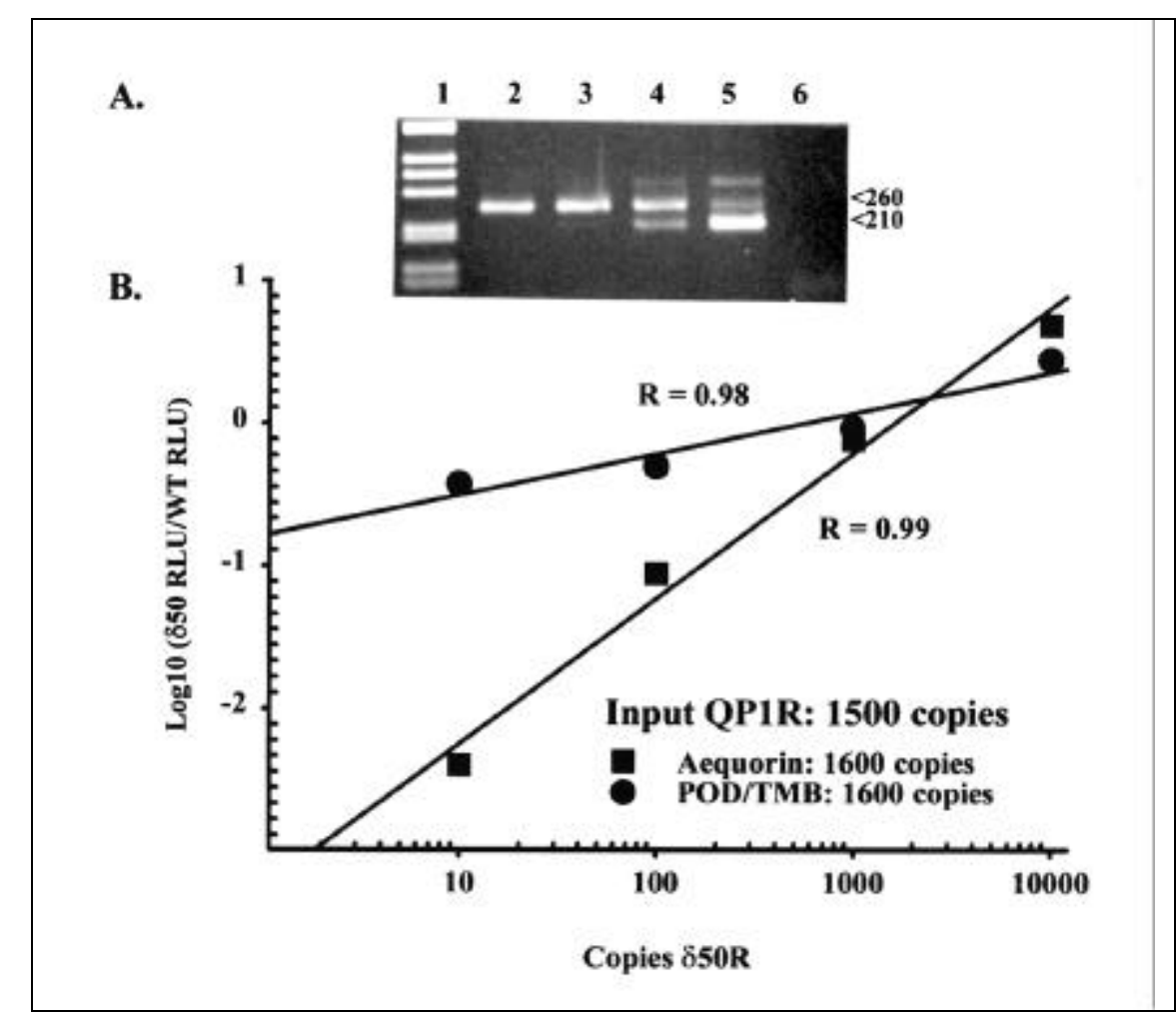

Figure 3. Comparison of aequorin- and peroxidase-based quantification of RT QC-PCR products. QP1 RNA (1500 copies) was spiked into four QC-PCRs containing 10, 100, 1000 and 10000 copies of 850R RNA internal standard. After RT QC-PCR, the four reactions were analyzed on a 3\% agarose gel stained with ethidium bromide (A), and by the aequorin- and peroxidase-based microplate detection assays (B). (A) Lane 1, 1-kb ladder size standards; lanes 2-5 each had 1500 copies of QP1 RNA, plus $\delta 50 \mathrm{R}$ at 10 copies (lane 2), 100 copies (lane 3), 1000 copies (lane 4), 10000 copies (lane 5) and 0 copies of QP1R and $850 \mathrm{R}$ (lane 6; negative control). The QP1R and $850 \mathrm{R}$ PCR products migrated at 260 and 210 bp, respectively. (B) The same PCR products used for Panel A were quantified with the peroxidase- and aequorin-based microplate detection assay. QP1R input was calculated at 1600 copies by both the aequorin- and peroxidase-based assays. 


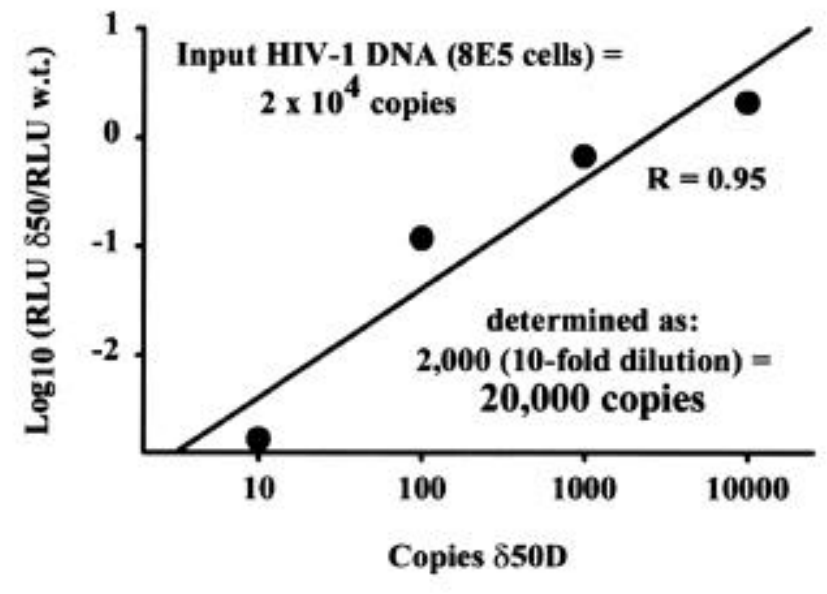

Figure 4. HIV-1 proviral DNA quantification by the QC-PCR/microplate detection assay. HIV-1infected 8E5 cells (20000) were added to $1 \mathrm{~mL}$ of a vaginal lavage mixture that was a combination of equal volumes of PBS vaginal lavages from three HIV-1-infected women. The cells were pelleted, and DNA was extracted as described. One-tenth of the DNA extract was used for each of four QC-PCRs containing 10, 100, 1000 and 10000 copies of the $\delta 50 \mathrm{D}$ internal standard. The diagonal line represents the linear regression curve used for the calculation of predicted proviral DNA copies as described in Materials and Methods. Pearson's correlation coefficient (R) was determined for the four data points generated by the QC-PCR determination of input proviral DNA.

sary to increase the range of values over which this assay would be useful. An increase in the range of OD values produced by the peroxidase enzyme detection of the $\delta 50$ internal standard would result in a linear regression curve with a greater slope, extending the usefulness of this assay in the upper and lower ranges.

A reliable microplate format for quantification of HIV-1 QC-PCR products was previously reported that uses aminated PCR products that are captured onto a carboxylated surface (12). In this procedure, free primers must be removed and the sample diluted before the aminated PCR products are attached to the carboxylated microplate wells. In our QC-PCR procedure, the biotinylated PCR products are transferred directly from a 96-well PCR plate to a streptavidin-coated, 96-well plate. Because all PCR reagents and internal standards are added to the 96well PCR plate with a multichannel pipetor, the efficiency of the QC-PCR setup is greatly increased. To avoid contamination of adjacent wells, the tubes in the row receiving the sample were uncapped, and tubes in all other rows were loosely capped. When this procedure and standard precautions for PCR were used, adjacent well-to-well contamination was not a recurring problem. We have also found that the deoxy UTP/UDP glycosylase method (14) to inactivate possible contamination by post-PCR products can be used in our system without affecting quantification results.

The initial test of our QC-PCR system that used human plasma from five HIV-1-seropositive persons indicated that the QC-PCR and bDNA signal amplification techniques gave very similar results over a wide range of viral loads from less than 10000 copies to approximately 500000 copies of HIV-1 RNA. The less than twofold difference between QC-PCR and bDNA in three samples that were quantifiable by bDNA and the quantification of lowlevel viral loads in the two samples by QC-PCR that were below the limit of quantification by bDNA, strongly suggest that our QC-PCR accurately measured HIV-1 RNA. A larger comparison study of plasma viral load will be necessary to determine how results from the QC-PCR/microplate quantification system compare to those derived from commercially available viral load assays that can detect low levels of HIV-1 RNA. However, this initial report on the development of the QC$\mathrm{PCR} / \mathrm{microplate}$ detection assay shows 
that HIV-1 virus in plasma and vaginal lavage, and HIV-1 proviral DNA can be efficiently and accurately quantified in a 96-well format with instrumentation available in most laboratories that perform PCR. It is anticipated that the modifications reported here of the original QC-PCR nucleic acid extraction procedures, internal standard and detection technique will provide an HIV1 quantification method that is highly adaptable for use in both plasma and extravascular fluids and cells.

\section{ACKNOWLEDGMENTS}

We would like to thank Dr. Renu Lal, Centers for Disease Control and Prevention, for providing HIV-1-seropositive plasma samples; Dr. Thomas C. Wright, Columbia University Medical Center, for providing the vaginal lavages; Dr. Tedd Ellerbrock, Centers for Disease Control and Prevention, and Dr. Jeffery Lennox, Emory University School of Medicine, for their assistance in acquiring the vaginal lavages.

\section{REFERENCES}

1.Bell, J. and L. Ratner. 1989. Specificity of polymerase chain reactions for human immunodeficiency virus type 1 DNA sequences. AIDS Res. Hum. Retroviruses 5:87-95.

2.Cao, Y., D.D. Ho, J. Todd, R. Kokka, M. Urdea, J.D. Lifson, M. Piatak, Jr., S. Chen, B.H. Hahn et al. 1995. Clinical evaluation of branched DNA signal amplification for quantifying HIV type 1 in human plasma. AIDS Res. Hum. Retroviruses 11:353-361.

3.Cassol, S., T. Salas, N. Lapointe, M. Arella, J. Rudnik, M. O'Shaughnessy. 1991. Improved detection of HIV-1 envelope sequences using optimized PCR and inosine substituted primers. Mol. Cell. Probes 5:157-160.

4.Coombs, R.W., A.C. Collier, J.-P. Allain, B. Nikora, M. Leuther, G.F. Gjerset and L. Corey. 1989. Plasma viremia in human immunodeficiency virus infection. N. Engl. J. Med. 321:1626-1631.

5.Cormier, M. J., D.C. Prasher, M. Longiaru and R.O. McCann. 1989. The enzymology and molecular biology of the $\mathrm{Ca}^{+2}$-activated photoprotein, aequorin. Photochem. Photobiol. 49:509-512.

6.Doran, C.M. 1997. New approaches to using antiretroviral therapy for the management of HIV infection. Ann. Pharmacother. 31:228236.

7.Folks, T.M., D. Powell, M. Lightfoote, S. Koenig, A.S. Fauci, S. Benn, A. Rabson, D. Daugherty, H.E. Gendelman et al. 1986. Biological and biochemical characterization of a cloned leu-3- cell surviving infection with the aquired immune deficiency syndrome virus. J. Exp. Med. 164:280-290.

8.Harrigan, R. 1995. Measuring viral load in the clinical setting. J. Acquir. Immune Defic. Syndr. Hum. Retrovirol. 10:S34-S40.

9.Hart, R.C., B.L. Scheuer, H.N. Rivera and J. Gray. 1993. A bioluminescent assay capable of detecting $<2$ attomoles of hTSH in serum using the recombinant calcium-triggered photoprotein, aequorin, p. 320-323. In Bioluminescence and Chemiluminescence: Status Report John Wiley \& Sons, Chichester.

10.Jurriaans, S., B. Van Gemen, G.J. Weverling, D. Van Strijp, P. Nara, R. Coutinho, M. Koot, H. Schuitemaker and J. Goudsmit. 1994. The natural history of HIV1 infection: virus load and virus phenotype independent determinants of clinical course? Virology 204:223-233.

11.Katzenstein, T.L., C. Pedersen, C. Nielsen, J.D. Lundgren, P.H. Jakobsen and J. Gerstoft. 1996. Longitudinal serum HIV RNA quantification: correlation to viral phenotype at seroconversion and clinical outcome. AIDS 10:167-173

12.Kohsaka, H., A. Taniguchi, D.D. Richman and D.A. Carson. 1993. Microtiter format gene quantification by covalent capture of competitive PCR products: application to HIV-1 detection. Nucleic Acids Res. 21:34693472 .

13.Lafeuillade, A., C. Poggi, N. Profizi, C. Tamalet and O. Costes. 1996. Human immunodeficiency virus type 1 kinetics in lymph nodes compared with plasma. J. Infect. Dis. 74:404-407.

14.Longo, M.C., M.S. Berninger and J.L. Hartley. 1990. Use of uracil DNA glycosylase to control carry-over contamination in polymerase chain reactions. Gene 93:125128.

15.Mellors, J.W., L.A. Kingsley, C.R. Rinaldo, Jr., J.A. Todd, B.S. Hoo, R.P. Kokka and P. Gupta. 1995. Quantitation of HIV-1 RNA in plasma predicts outcome after seroconversion. Ann. Intern. Med. 122:573-579.

16.Mellors, J.W., C.R. Rinaldo, Jr., P. Gupta, R.M. White, J.A. Todd and L.A. Kingsley. 1996. Prognosis of HIV-1 infection by the quantity of virus in plasma. Science 272:1167-1170.

17.Mulder, J., N. McKinney, C. Christopherson, J. Sninsky, L. Greenfield and S. Kwok. 1994. Rapid and simple PCR assay for quantitation of human immunodeficiency virus type 1 RNA in plasma: application to acute retroviral infection. J. Clin. Microbiol. 32:292-300.

18.Mullis, K.G. and F.A. Faloona. 1987. Specific synthesis of DNA in vitro via a polymerase catalyzed chain reaction. Methods Enzymol. 155:263-273

19.Myers, G., B. Korber, J.A. Berzofsky, R.F. Smith and G.N. Pavlakis (Eds.). 1991. Human Retroviruses and AIDS. A Compilation and Analysis of Nucleic Acid and Amino Acid Sequences. Los Alamos National Laboratory, Los Alamos.

20.Pantaleo, G., C. Graziosi, L. Butini, P.A. Pizzo, S.M. Schnittman, D.P. Kotler and A.S. Fauci. 1991. Lymphoid organs function as major reservoirs for human immunodeficiency virus. Proc. Natl. Acad. Sci. USA
88:9838-9842

21.Pantaleo, G., C. Graziosi, J.F. Demarest, L. Butini, M. Montroni, C.H. Fox, J.M. Orenstein, D.P. Kotler and A.S. Fauci. 1993. HIV infection is active and progressive in lymphoid tissue during the clinically latent stage of disease. Nature 362:355-358.

22.Piatak, M., Jr., K.-C. Luk, B. Williams and J.D. Lifson. 1993. Quantitative competitive polymerase chain reaction for accurate quantitation of HIV DNA and RNA species. BioTechniques 14:70-81.

23.Piatak, M., Jr., M.S. Saag, L.C. Yang, S.J. Clark, J.C. Kappes, K.-C. Luk, B.H. Hahn, G.M. Shaw and J.D. Lifson. 1993a. Determination of plasma viral load in HIV-1 infection by quantitative competitive polymerase chain reaction. AIDS 7:S65-S71.

24.Piatak, M., Jr., S. Saag, L.C. Yang, S.J. Clark, J.C. Kappes, K.-C. Luk, B.H. Hahn, G.M. Shaw and J.D. Lifson. 1993b. High levels of HIV-1 in plasma during all stages of infection determined by competitive PCR. Science 259:1749-1754.

25.Prasher, D., R.O. McCann and M.J. Cormier. 1985. Cloning and expression of the cDNA coding aequorin, a bioluminescent calciumbinding protein. Biochem. Biophys. Res. Commun. 126:1259-1268.

26.Prendergast, F.G. and K.G. Mann. 1978. Chemical and physical properties of aequorin and the green fluorescent protein isolated from Aequorea forskalea. Biochemistry 17:3448-3453

27.Shimomura, O., F.H. Johnson and Y. Saiga. 1962. Extraction, purification and properties of aequorin, a bioluminescent protein from the luminous hydromedusan, Aequorea. J. Cell. Physiol. 59:223-240.

28.Stults, N.L., N.A. Stocks, H. Rivera, J. Gray, R. McCann, D. O'Kane, R.D. Cummings, M.J. Cormier and D.F. Smith. 1992. Use of recombinant aequorin in microtiter and membrane-based assays. Biochemistry 31:1433-1442.

29.Urdea, M.S., J.C. Wilber, T. Yeghiazarian, J.A. Todd, D.G. Kern, S.-J. Fong, D. Besemer, B. Hoo, P.J. Sheridan et al. 1993. Direct and quantitative detection of HIV-1 RNA in human plasma with a branched DNA signal amplification assay. AIDS 7:S11-S14.

30.Varma, V.A., S. Hunter, R. Tickman, A. Srinivasan and D. Swan. 1989. Acute fatal HIV encephalitis with negative serologic assays for antibody and antigen: diagnosis by polymerase chain reaction. N. Engl. J. Med. 320:1494-1495.

Received 7 April 1997; accepted 7 January 1998.

Address correspondence to:

Patricia C. Guenthner

Retrovirus Diseases Branch

DASTLR/NCID

Mail stop $G 19$

1600 Clifton Road, NE Atlanta, GA 30333, USA

Internet:pcg1@cdc.gov 